\title{
Factors Influencing Subjective Orthodontic Treatment Need and Culture-related Differences among Chinese Natives and Foreign
}

\section{Inhabitants}

\author{
Xiao-ting $\mathrm{Li}^{1}$, Yin Tang ${ }^{2}$, Xue-lian Huang ${ }^{2}$, Hua Wan ${ }^{3}$, Yang-xi Chen ${ }^{1 *}$ \\ ${ }^{1}$ Department of Orthodontics, West China College of Stomatology, Sichuan University, Chengdu, China \\ ${ }^{2}$ Department of Operative Dentistry and Endodontics, West China College of Stomatology, Sichuan University, Chengdu, \\ China \\ ${ }^{3}$ Department of Health Statistics, West China College of Public Health, Sichuan University, Chengdu, China
}

\begin{abstract}
Aim The aim of this survey was to compare Chinese natives and foreign inhabitants in Chengdu, China, with respect to: (1) attitudes towards dental appearance, (2) subjective orthodontic treatment need, and (3) the main factors influencing orthodontic treatment need.
\end{abstract}

Methodology A total of 522 subjects, including 227 foreign inhabitants and 295 Chinese natives in Chengdu participated in the survey. A simple random sampling method was adopted and a face-to-face interview was conducted at some public sites using a questionnaire. Data was entered by two persons synchronously using Epidata 3.0, and SPSS 13.0 was used to analyze these data.

Results $89.0 \%$ of foreign inhabitants were satisfied with their teeth compared to only $46.8 \%$ of Chinese natives. Females were more dissatisfied with their teeth than males. Chinese natives put improving appearance as the top priority $(55.9 \%)$ for seeking orthodontic treatment; however, in foreign inhabitants, the main reason for seeking treatment was to improve masticatory function
(44.1\%), followed by "to be pretty" (35.2\%). The importance of well-aligned teeth and self-perception of psychosocial impact of malocclusion were the same two main factors influencing subjective orthodontic treatment need $(P<0.05)$ in foreign inhabitants and Chinese natives. Subjective orthodontic treatment need between the two target groups was significantly different $(P<0.05)$.

Conclusion (1) It was very common that Chinese natives were dissatisfied with their dental appearance, and their subjective orthodontic treatment needs were high. (2) There were some differences in orthodontic treatment motives between the two target groups. (3) There were differences in subjective orthodontic treatment needs between foreign inhabitants and Chinese natives. However, the prominent influential factors were almost the same. There may be benefit to understanding subjective orthodontic needs of different races.

Keywords orthodontic treatment, motives, subjective needs, comparative study

Received Jan. 6, 2010; Revision accepted Apr. 17, 2010

\section{Introduction}

With the rapid development of the society and economy of China, Chinese people have gradually paid more attention to quality of life, especially associated with the impact of dental conditions (Wang et al., 1998). Desire for orthodontic treat- ment is increasing and the reason for this should not be underestimated. Evidence suggests that people who express dissatisfaction with their teeth may have some psychological problems which may impact their social behavior (Cash and Fleming, 2002). Those who are satisfied with their teeth seem to be more self-confident and have 
higher self-esteem. Therefore, seeking orthodontic treatment is considered a way to improve dentofacial appearance and gain self-confidence.

The city of Chengdu is one of the most vigorous cities in China. Because of its unique geographic location and abundant tourism resources, plenty of foreigners flock to Chengdu every year. They mainly engage in business or education, and many of them choose to work for a long time or settle down here because Chengdu is a suitable and ideal city in which to live. This large proportion of foreign inhabitants will inevitably suffer some dental problems. However, there are currently few surveys studying foreign inhabitants' expectation of dental needs in China, especially orthodontic treatment needs.

Self-perception and satisfaction with one's teeth had been studied by Elham (Elham et al., 2005). It was found that females and older school children considered their teeth as more attractive than males and younger children. The demand for orthodontic treatment was found to be affected by gender.

In previous studies, the motives of seeking orthodontic treatment have also been analyzed. Phillips found a strong social motivation occurred among males more than among females, while a higher proportion of females focused on improving appearance (Phillips et al., 1997). Similar results were presented by Birkeland who found that aesthetic motives were the most frequently reported subjective reason for orthodontic care (Birkeland et al., 1999). In a study comparing adolescents and teens in the United States, with those in Japan and China, appearance was also the primary characteristic noticed by American students, whereas Japanese and Chinese students were more focused on specific behaviors in others (Crystal et al., 1998).

Subjective orthodontic treatment need was affected by many individual factors. Cultural, educational, gender differences, or access to orthodontic treatment all influenced patients' subjective needs. Josefsson investigated subjective orthodontic treatment needs in adolescents of Swedish and immigrant backgrounds, and found that the needs were significantly higher in the Swedish than immigrant groups (Josefsson et al., 2005; 2009). In Christopherson's research on children from minority backgrounds in the United States who had limited or no access to orthodontic treatment, black children were less happy with their smile than White children, and wanted braces more than White children (Christopherson et al., 2009). In the study by Burden concerning the factors which influenced the uptake of orthodontic treatment, the results indicated that self-perception of dental appearance, desire to look attrative, self-esteem, gender, and age were factors influencing the uptake of orthodontic treatment (Burden, 1995). Another study by Annemieke had found significant correlations between satisfaction with dental appearance and patients' expectations (Annemieke et al., 2003). No significant correlations were found among gender and expectations of orthodontic treatment. Another study also showed no gender difference in the population seeking orthodontic treatment (Burder et al., 1994). A meta-analysis found that a positive relationship existed between facial attractiveness and interpersonal popularity, as well as others' favourable evaluation of one's personality, social behaviour, and intellectual expression (Hosoda et al., 2003). Thus, psychosocial impact of malocclusion may also be a factor that affected subjective orthodontic treatment needs (Langlois et al., 2000).

In Chengdu City, Chinese natives and foreign inhabitants may have different orthodontic treatment expectations because of their different cultural and educational backgrounds. Comparing their different subjective orthodontic treatment need and studying influencial factors will provide a guide for China's orthodontic education, but may also be helpful in addressing foreign inhabitants with their orthodontic problems. The aim of this survey was to compare Chinese natives and foreign inhabitants in Chengdu, China, with respect to: (1) attitudes towards dental appearance, (2) subjective orthodontic treatment need, and (3) the main factors influencing orthodontic treatment need.

\section{Materials and Methods}

\section{Subjects and sampling method}

The survey was divided into two periods. The first period was carried out from May to July in 
2008 and the target population was foreign inhabitants in the city of Chengdu. The urban areas of Chengdu have nine subordinate districts. From the Bureau of Public Security, we determined that foreign inhabitants were distributed throughout five subordinate districts. Our research team investigated some public sites, such as restaurants, international schools, communities, and some famous tourist resorts in these five districts. Questionnaires written in English were randomly sent out and a face-to-face interview was conducted between the investigator and the participants. In every subordinate district, 50 foreign inhabitants were selected to complete the questionnaires.

The second survey was carried out from August to October, 2008 and the target population was the natives in Chengdu. We first acquired lists of all nine subordinate districts and all the community neighborhoods of Chengdu. Two neighborhoods were randomly selected in each subordinate district, resulting in a total of 18 neighborhoods being selected. From every selected neighborhood, 20 natives were selected with face-to-face interviews.

Inclusion criteria included a willingness to provide informed consent and complete the survey, and age from 18 to 64 years.

\section{Questionnaire}

The questionnaire included the following items:

1. Demographic data (gender, age, profession, educational background, self-satisfaction with the teeth, the importance of well-aligned teeth, awareness of others' teeth, motives of seeking orthodontic treatment, and self-perception of psychosocial impact of malocclusion)

2. Self-satisfaction with their teeth

3. Importance of well-aligned teeth

4. Awareness of others' teeth

5. Subjective orthodontic treatment need

6. Motivation of seeking orthodontic treatment (to improve masticatory function and to be healthy/ to be pretty/to be acceptable to the society)

7. Self-perception of psychosocial impact of malocclusion

\section{Reliability test}

35 university students were selected at random and were presented with the same questionnaire after an interval of four weeks, under the same circumstances. For the analysis of reliability, the Kappa value was used. Their initial answers were included in the study.

The demographic data was the same between the two tests. In the remaining items, a Kappa value of 0.873 in one item represented that near perfect agreement was achieved. Substantial agreement was attained in other six items with Kappa value between $0.63-0.72$ during the two tests. This indicates that the consistency and reliability of this survey was very high (Landis and Koch, 1977).

\section{Statistical methods}

The data was entered by two persons synchronously using Epidata 3.0, and SPSS 13.0 was used to analyze the data.

One dependent and nine independent variables were selected from the questionnaire. Chi-square test was used to examine the correlation between nine independent variables and the dependent one. Forward stepwise logistic analysis was subsequently used to select the statistically significant variables and to determine the main factors influencing subjective orthodontic treatment need. Significance was set at $P<0.05$.

\section{Results}

A total of 522 participants including 227 foreign inhabitants and 295 natives in Chengdu completed the questionnaire. The study foreign inhabitants came from more than 30 countries (see Figure 1).

The distribution of participants by demographic characteristics and their attitudes towards dental appearance are shown in Table 1.

Among 227 foreign habitants, the "18-24", "25-34" age strata were the largest proportions. "18-24" was $24.7 \%$, and "25-34" was $27.8 \%$. $39.2 \%$ of them came from North America, $36.1 \%$ came from Europe, while $24.7 \%$ came from other countries and districts. Among 295 Chinese natives, "18-24" accounted for $36.6 \%$ proportion and " $25-34$ " were $37.6 \%$ of the sample, which conformed to population composition of China.

Regarding self-satisfaction with the teeth, $89.0 \%$ 


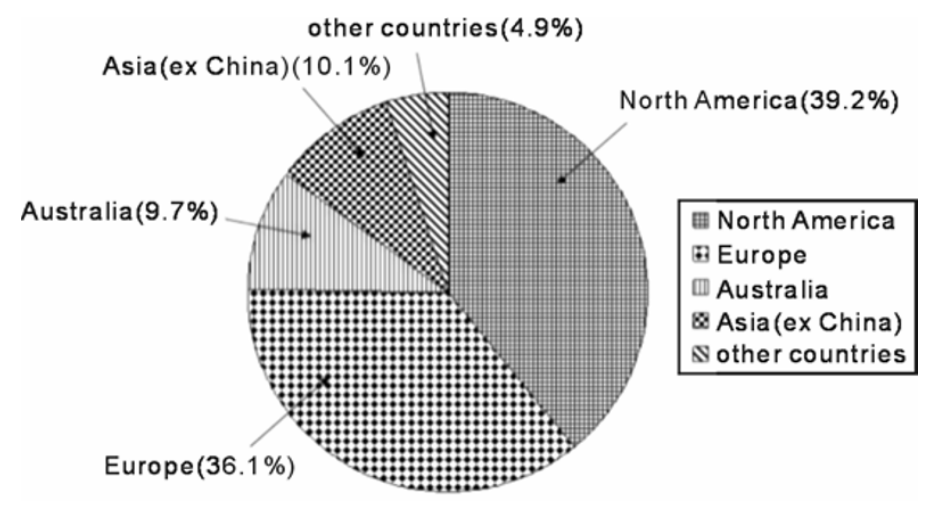

Figure 1 Distribution of the countries of foreign inhabitants

Table 1 Demographic characteristics and attitudes towards dental appearance

\begin{tabular}{|c|c|c|}
\hline & $\begin{array}{c}\text { foreign } \\
\text { inhabitants } \\
(n=227)\end{array}$ & $\begin{array}{l}\text { natives } \\
(n=295)\end{array}$ \\
\hline \multicolumn{3}{|l|}{ Gender } \\
\hline Male & $144(63.4 \%)$ & $154(52.2 \%)$ \\
\hline Female & $83(36.6 \%)$ & $141(47.8 \%)$ \\
\hline \multicolumn{3}{|l|}{ Age } \\
\hline $55-64$ & $9(4.0 \%)$ & $3(1.0 \%)$ \\
\hline $45-54$ & $46(20.3 \%)$ & $12(4.1 \%)$ \\
\hline $35-44$ & $53(23.3 \%)$ & $61(20.7 \%)$ \\
\hline $25-34$ & $63(27.8 \%)$ & $111(37.6 \%)$ \\
\hline $18-24$ & $56(24.7 \%)$ & $108(36.6 \%)$ \\
\hline \multicolumn{3}{|l|}{ Profession } \\
\hline Governor & $68(30.0 \%)$ & $42(14.2 \%)$ \\
\hline Student & $55(24.2 \%)$ & $113(38.3 \%)$ \\
\hline Company staff & $35(15.4 \%)$ & $64(21.7 \%)$ \\
\hline Technician & $42(18.5 \%)$ & $38(12.9 \%)$ \\
\hline Others & $27(11.9 \%)$ & $38(12.9 \%)$ \\
\hline \multicolumn{3}{|c|}{ Education backgrounds } \\
\hline Lower education & $32(14.1 \%)$ & $63(21.3 \%)$ \\
\hline Middle education & 77 (33.9\%) & $84(28.5 \%)$ \\
\hline Higher education & $118(52.0 \%)$ & $148(50.2 \%)$ \\
\hline \multicolumn{3}{|c|}{$\begin{array}{l}\text { Self-satisfaction with the } \\
\text { teeth }\end{array}$} \\
\hline Yes & $202(89.0 \%)$ & $138(46.8 \%)$ \\
\hline No & $25(11.0 \%)$ & $157(53.2 \%)$ \\
\hline \multicolumn{3}{|c|}{$\begin{array}{l}\text { Importance of well-aligned } \\
\text { teeth }\end{array}$} \\
\hline Yes & $205(90.3 \%)$ & $278(94.2 \%)$ \\
\hline No & $22(9.7 \%)$ & $17(5.8 \%)$ \\
\hline
\end{tabular}

of foreign inhabitants were satisfied with their teeth, and $11.0 \%$ were dissatisfied. However, only $46.8 \%$ of Chinese natives were satisfied while $53.2 \%$ were dissatisfied. Of the two target groups, more than $90 \%$ considered that well-aligned teeth were very important. The age distribution of selfsatisfaction with the teeth is shown in Figure 2 and Figure 3.

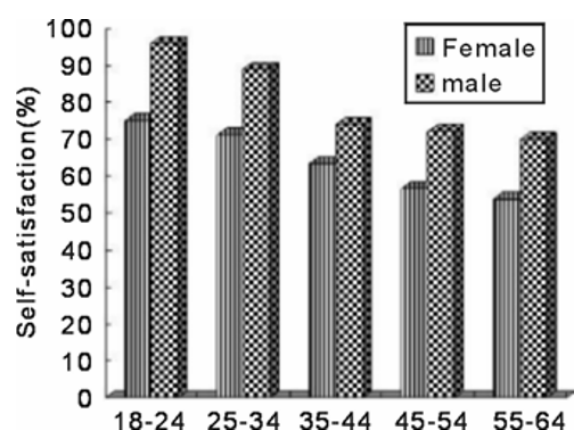

Figure 2 Age distribution of self-satisfaction with the teeth in foreign inhabitants

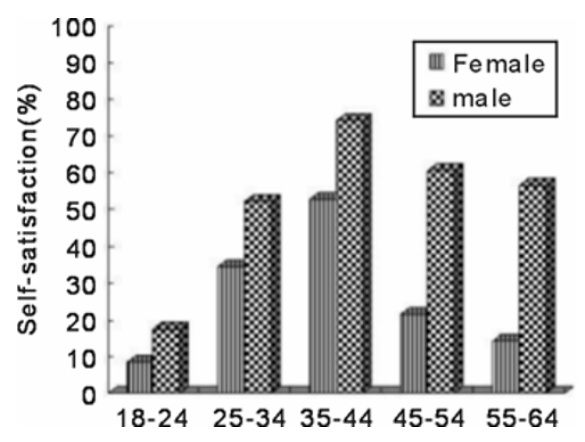

Figure 3 Age distribution of self-satisfaction with the teeth in Chinese natives 
As is seen from Figure 2 and Figure 3, men were more often satisfied than women among all age groups. Of all foreign inhabitants, there was a decreased satisfaction with teeth with increasing age. However, dissatisfaction was more common among Chinese natives. Especially in the "18-24" age stratum, only $17.6 \%$ of males and $8.5 \%$ of females were satisfied with their teeth.

The desire for seeking orthodontic treatment showed some differences between foreign inhabitants and Chinese natives. A total of $44.1 \%$ of foreign inhabitants regarded improving masticatory function as the first consideration, and also $35.2 \%$ considered improving appearance. Nevertheless, more than half of Chinese natives (55.9\%) reckoned improving appearance as the most important reason for orthodontic treatment (Figure 4).

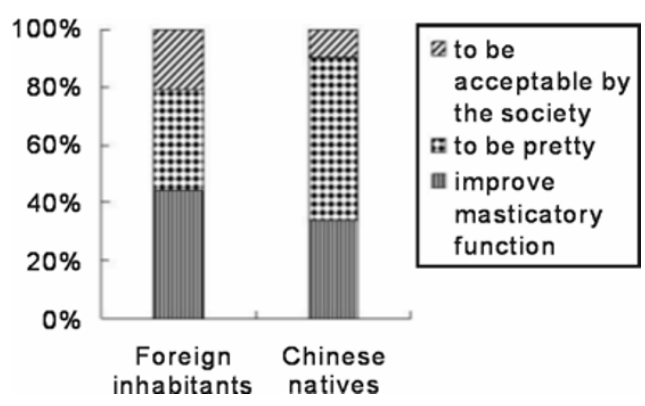

Figure 4 Different motives of orthodontic treatment of subjects

Referring to self-perception of malocclusion impact, both foreign inhabitants and Chinese natives held the standpoint that a good look of oral and facial appearance had a positive impact on their social behavior and communication. The percentage was $80.6 \%$ and $86.8 \%$, separately. In total, $59.9 \%$ of foreign inhabitants agreed that malocclusion had a negative effect on psychology. Relatively more Chinese natives (73.9\%) supported this view.

\section{Factors influencing subjective orthodontic treat- ment}

One dependent variable, subjective orthodontic treatment need, was selected from the questionnaire. And nine other independent variables also derived from it included gender, age, profession, educational background, self-satisfaction with the teeth, the importance of well-aligned teeth, aware- ness of others' teeth, motives of seeking orthodontic treatment, and self-perception of psychosocial impact of malocclusion.

All the nine independent variables were separately brought into the chi-square test to determine crude associations with the dependent variable. The results are shown in Table 2.

Table 2 Chi-square test of independent variables and subjective orthodontic treatment need

\begin{tabular}{|c|c|c|}
\hline \multirow[b]{2}{*}{ Variables } & \multicolumn{2}{|c|}{$P$ value } \\
\hline & $\begin{array}{c}\text { Foreign } \\
\text { inhabitants } \\
(n=227)\end{array}$ & $\begin{array}{l}\text { Natives } \\
(n=295)\end{array}$ \\
\hline Importance of well-aligned teeth & 0.000 & 0.000 \\
\hline Awareness of others' teeth & 0.045 & 0.001 \\
\hline $\begin{array}{l}\text { Self-perception of psychosocial } \\
\text { impact of malocclusion }\end{array}$ & 0.008 & 0.000 \\
\hline \multicolumn{3}{|c|}{ Chi-square test with exit criteria of $P=0.05$. } \\
\hline \multicolumn{3}{|c|}{$\begin{array}{l}\text { All the nine independent variables brought into chi-square test } \\
\text { at the beginning. }\end{array}$} \\
\hline \multicolumn{3}{|c|}{$\begin{array}{l}\text { Importance of well-aligned teeth, awareness of others' teeth, } \\
\text { self-perception of psychosocial impact of malocclusion were } \\
\text { significant }(P<0.05) \text { and the others were not significant }\end{array}$} \\
\hline
\end{tabular}

Of two target groups, the same three independent variables had statistical significance. They were importance of well-aligned teeth, awareness of others' teeth, and self-perception of psychosocial impact of malocclusion. Other variables such as gender, age, profession, educational background, self-satisfaction with the teeth, and motivation of seeking orthodontic treatment were not found to be associated with subjective orthodontic treatment.

Forward stepwise logistic analysis was subsequently used to select the main influential factors among these three statistically significant variables. This analysis was also made separately in two target groups. The results are shown in Table 3 and Table 4.

The results of forward stepwise logistic analysis showed that the importance of well-aligned teeth and self-perception of psychosocial impact of malocclusion were the two main factors influencing subjective orthodontic treatment need $(P<0.05)$ in foreign inhabitants and Chinese natives in Chengdu. 
Table 3 Forward stepwise logistic analysis of statistically significant variables and self-perceived orthodontic treatment need of foreign inhabitants $(n=227)$

\begin{tabular}{llcccccc}
\hline & & B & S.E. & Wald & df & $P$ & RR \\
\hline Step 1(a) & Socio-behavioural impact & 1.716 & 0.380 & 20.405 & 1 & 0.000 & 5.562 \\
& Constant & -3.706 & 0.547 & 45.896 & 1 & 0.000 & 0.025 \\
Step 2(b) & Importance of well-aligned teeth & 1.625 & 0.505 & 10.344 & 1 & 0.001 & 5.077 \\
& Self-perception of psychosocial impact & 1.470 & 0.400 & 13.476 & 1 & 0.000 & 4.349 \\
& of malocclusion & & & & & & \\
& Constant & -5.246 & 0.773 & 46.070 & 1 & 0.000 & 0.005 \\
\hline
\end{tabular}

Forward stepwise logistic analysis with exit criteria of $P=0.05$. a: Variable(s) entered on step 1: b9. b: Variable(s) entered on step 2: b2. All the three statistically significant variables brought into forward stepwise logistic analysis at the beginning. Importance of well-aligned teeth, self-perception of psychosocial impact of malocclusion were significant $(P<0.05)$ and the others were not significant $(P>0.05)$.

Table 4 Forward stepwise logistic analysis of statistically significant variables and self-perceived orthodontic treatment need of Chinese natives $(n=295)$

\begin{tabular}{llcccccc}
\hline & & B & S.E. & Wald & df & $P$ & RR \\
\hline Step 1(a) & Importance of well-aligned teeth & 2.788 & 0.544 & 26.305 & 1 & 0.000 & 16.250 \\
& Constant & -5.458 & 0.688 & 62.894 & 1 & 0.000 & 0.004 \\
Step 2(b) & Importance of well-aligned teeth & 2.039 & 0.609 & 11.233 & 1 & 0.001 & 7.687 \\
& Self-perception of psychosocial impact & 1.599 & 0.495 & 10.456 & 1 & 0.001 & 4.950 \\
& of malocclusion & & & & & & \\
& Constant & -6.601 & 0.844 & 61.126 & & & 0.000 \\
\end{tabular}

Forward stepwise logistic analysis with exit criteria of $P=0.05$. a: Variable(s) entered on step 1: b2. b: Variable(s) entered on step 2: b9. All the three statistically significant variables brought into forward stepwise logistic analysis at the beginning. Importance of well-aligned teeth, self-perception of psychosocial impact of malocclusion were significant $(P<0.05)$ and the others were not significant $(P>0.05)$.

\section{The difference of subjective orthodontic treat- ment need between groups}

Of the 227 foreign participants, $81.9 \%$ wanted to receive orthodontic treatment, while of the 295 Chinese native subjects, $90.8 \%$ had the same desire. Chi-square test between the two target groups showed that this difference had statistical significance $(P<0.05)$. The Chinese natives had a little higher expectation to receive orthodontic treatment than foreign inhabitants.

Combining the data of two target groups, the subjects were then divided into two subdivisions: developed countries and developing countries. Of these, $94.4 \%$ of participants from developed countries had the expectation to receive orthodontic treatment, while $89.8 \%$ of participants from developing countries did. Chi-square test showed no statistical significance $(P>0.05)$.

\section{Discussion}

The majority of Chinese people are dissatisfied with their teeth, and only $46.8 \%$ of them satisfy. The reason for this is likely that more and more Chinese people are aware of their dental health associated with their quality of life. However, a dental health prevention system may not be maintained. Many Chinese have certain dental problems including malocclusion, so they are dissatisfied with their teeth. In this survey, most foreign inhabitants came from North America and Europe. These countries have had a long tradition of paying attention to citizens' dental health. Therefore, their self-perception of dental appearance was higher than that of Chinese natives.

Tuominen et al. found among young Finnish adults, men were more often satisfied with their 
dentition than women (Tuominen et al., 1994). In earlier years, Shaw studied children regarding their feelings about dental appearance, finding that dissatisfaction with dental appearance was more common among females than males (Shaw, 1981). And this dissatisfaction was associated with increasing age. Our research found similar results. Both in foreign inhabitants and Chinese natives, it is common that men are more satisfied with their teeth than women. In foreign inhabitants, with age increasing, their satisfaction with teeth decreases, especially in females. This finding is consistent with Shaw's study (Shaw, 1981). In Chinese natives, the population most dissatisfied with their dental appearance is young people. This indicates that among Chinese young people, there is a tendency that aesthetics of dental appearance are receiving more and more attention, and their higher dental demands and needs should not be neglected.

In this survey, Chinese natives put improving appearance the top priority (55.9\%) for seeking orthodontic treatment; however, in foreign inhabitants, the main reason was to improve masticatory function (44.1\%), followed by "to be pretty" (35.2\%). Several previous studies have also found that the commonest reason for orthodontic treatment was to improve appearance (Shaw, 1991; Tuominen et al., 1994; Riedmann et al., 1999). In Germany, Riedmann et al. found that the orthodontic treatment demand was mainly influenced by the desire for improvement in appearance rather than for an improvement in chewing function. (Riedmann et al., 1999). The same results were found in CHU's research of Chinese young adults in Hong Kong (Chu et al., 2009). Their commonlyheld reasons for orthodontic treatment were to improve appearance (78\%), self-image (36\%), selfconfidence $(34 \%)$, as well as to follow parental advice (24\%). Other studies in North China also found that good appearance was the most common reason for orthodontic treatment (Huang et al., 2002; Chen et al., 2003).

This is the first study to compare the subjective orthodontic influential factors between foreign inhabitants and Chinese natives in China. The results show that the two groups have the same main factors influencing seeking orthodontic treatment, these being well-aligned teeth and selfperception of psychosocial impact of malocclusion.
Age, gender, and educational background do not affect subjective orthodontic treatment need.

For many years, the determining factors that influence subjective orthodontic treatment need are controversial. Burden (1995) found that selfperception of dental appearance, desire to look attractive, self-esteem, gender and age were the factors influencing the uptake of orthodontic treatment. It is also supported by Hagg's study (Hagg et al., 2001), which suggested that females have a higher demand and need for subjective orthodontic treatment. In China, Du et al. (2008) investigated the knowledge concerning orthodontic treatment in the Beijing area. They also found a gender difference in teeth concerns with the percentage of women being higher than men. Wang et al. (1998) investigated the influential factors for orthodontic treatment of adolescents in the city of Xi'an, and showed that gender and psychosocial factors played an important role.

Although in our study gender is not the prominent factor influencing subjective orthodontic treatment need, as many researchers have suggested, orthodontists should keep gender differences in mind when communicating with their patients. Annemieke et al. (2003) also pointed out that if samples of the survey had been larger, there might have been statistically significant correlations, as expected.

Overall, $59.9 \%$ of foreign habitants and $73.9 \%$ of Chinese natives in this survey considered that malocclusion will affect psychological development. Recently, there has been growing acceptance of aesthetics and its psychosocial impact as an important orthodontic treatment benefit (Cunningham and Hunt, 2001; Hunt et al., 2001). Malocclusions may result in impaired craniomandibular function and have an unfavourable influence on facial and dental attractiveness, which may in turn have psychological and socio-behavioural implications (Linder-Aronson et al., 2002).

This study is the first to compare subjective orthodontic treatment needs between Chinese and other races. The results show Chinese natives in Chengdu have a little higher expectation to receive orthodontic treatment than foreign habitants. One reason for this may be that there is a culturallyrelated difference in the two target groups. Their different economic development, social-cultural 
environment, and educational backgrounds may cause their different oral health and dental appearance attitudes and beliefs. Lew (1993), from Singapore, pointed out that several cross-cultural differences existed in the attitudes of Chinese compared to those reported in Caucasians. Mandall et al. (2000) reported that Asians do not seem disadvantaged compared with Caucasians with respect to the use of orthodontic services. Asians and females had higher orthodontic treatment needs than Caucasians and males. The other reason is that dental service system in China may not be suitable for foreign inhabitants. Thus, some of them do not want to seek dental services in China. The current circumstances may be ameliorated as China is changing to a multi-cultural society and sanitation is improving constantly.

Our study provides a rough description about subjective orthodontic treatment needs among foreign inhabitants and Chinese natives in Chengdu, China. This study indicates that the governors and orthodontists should take more effective measures to meet people's increasing orthodontic needs, including foreign inhabitants. However, the study has some limitations in sample selection. The sample should be larger, and a multicenter study is needed to explore other factors influencing subjective orthodontic treatment needs. Also, the objective orthodontic treatment needs of foreign inhabitants and Chinese natives should receive more attention. Objective and subjective assessment together will fully reveal orthodontic treatment needs of foreign inhabitants and Chinese natives, and give better guidance to orthodontists.

\section{Conclusions}

It was very common that Chinese natives were dissatisfied with dental appearance. More Chinese natives chose orthodontic treatment for aesthetic reasons, which indicates that the subjective orthodontic treatment needs of Chinese natives are increasing.

Foreign inhabitants were more satisfied with dental appearance. And there were some differences in orthodontic treatment motives between the two target groups, which indicates that different cultural and educational backgrounds might cause different orthodontic beliefs and attitudes.

There were differences in subjective orthodontic treatment needs between foreign inhabitants and Chinese natives. However, the prominent influential factors were almost the same.

\section{Acknowledgement}

This study was supported by the Sichuan University Students' Scientific Research Project. The authors are grateful to the teammates for their assistance during the survey. In addition, we acknowledge Prof. Zong-dao Shi, West China College of Stomatology, Sichuan University, and Miss Hua Wan, West China College of Public Health, for their assistance and valuable comments on statistical analysis.

\section{References}

Wang XR, Ye XY, Niu BP (1998). The influential factors to the motivation of orthodontic treatment in Chinese adolescent. J Pract Stomatol, 14(3): 214-216.

Cash TF, Fleming EC (2002). Body image issues and social relations/Cash TF ed. Body image: a handbook of theory, research, and clinical practice. New York: Guilford. pp.277-286.

Elham SJ, Alhaija A, Kazem S (2005). Self-perception of malocclusion among north Jordanian school children. Eur J Orthod, 27(3): 292-295.

Phillips C, Broder HL, Bennett ME (1997). Dentofacial disharmony: motivations for seeking treatment. Int $J$ Adult Orthod Orthog Surg, 12(1): 7-15.

Birkeland K, Katle A, Løvgreen S, Bøe OE, Wisth PJ (1999). Factors influencing the decision about orthodontic treatment. A longitudinal study among 11- and 15-year-olds and their parents. J Orofac Orthop, 60(5): 292-307.

Crystal DS, Watanabe H, Weinfurt K, Wu C (1998). Concepts of human differences: a comparison of American, Japanese and Chinese children and adolescents. Devel Psychol, 34(4): 714-722.

Josefsson E, Bjerklin K, Halling A (2005). Self-perceived orthodontic treatment need and culturally related differences among adolescents in Sweden. Eur J Orthod, 27(2): 140-147.

Josefsson E, Bjerklin K, Lindsten R (2009). Factors determining perceived orthodontic treatment need in 
adolescents of Swedish and immigrant background. Eur J Orthod, 31(1): 95-102.

Christopherson EA, Briskie D, Inglehart MR (2009). Objective, subjective, and self-assessment of preadolescent orthodontic treatment need - a function of age, gender, and ethnic/racial background? J Public Health Dent, 69(1): 9-17.

Burden DJ (1995). The influence of social class, gender and peers on the uptake of orthodontic treatment. Eur $J$ Orthod, 17(3): 199-203.

Annemieke B, Johan H, Birte PA (2003). Expectation of treatment and satisfaction with dentofacial appearance in orthodontic patients. Am J Orthod Dentofacial Orthop, 123(2): 127-132.

Burder DJ, Mitropoules CM, Shaw WC (1994). Residual orthodontic treatment need in a sample of 15- and 16-year olds. Br Dent J, 176(6): 220-224.

Hosoda M, Stone-Romero E, Coats G (2003). The effect of physical attractiveness on job-related outcomes: a metaanalysis of experimental studies. Personnel Psychol, 56(2): 431-462.

Langlois JH, Kalakanis L, Rubenstein AJ, Larson A, Hallam M, Smoot M (2000). Maxims or myths of beauty? A meta-analytic and theoretical review. Psychol Bull, 126(3): 390-423.

Landis JR, Koch GG (1977). The measurement of observe agreement for categorical data. Biometrics, 33(1): 159-174.

Tuominen ML, Tuominen RJ, Nyström ME (1994). Subjective orthodontic treatment need and perceived dental appearance among young Finnish adults with and without previous orthodontic treatment. Community Dent Health, 11(1): 29-33.

Shaw WC (1981). Factors influencing the desire for orthodontic treatment. Eur J Orthod, 3: 151-162.

Riedmann T, Geog T, Berg R (1999). Adult patient's view of orthodontic treatment outcome compared to pro- fessional assessment. J Orofac Orthop, 60(5): 308-320.

Shaw WC, O'Brien KD, Richmond S (1991). Quality control in orthodontics: factors influencing the receipt of orthodontic treatment. Br Dent J, 19(2): 66-68.

Chu CH, Choy BH, Lo EC (2009). Occlusion and orthodontic treatment demand among Chinese young adults in Hong Kong. Oral Health Prev Dent, 7(1): 83-91.

Huang XF, Zhang D, Wang Z (2002). The demand and motivation of orthodontic patients in Beijing. Chin $J$ Orthod, 9(3): 121-123.

Chen YP, Hu M, Bi CQ, Sun HL, Yang LY, Feng XD,et al. (2003). A survey of adults' motivation for orthodontic therapy. J Modern Stomatol, 17(4): 346-348.

Hagg U, Yip ACK, Rabie AB (2001). The orthodontic treatment need and demand of young Chinese adults versus children. Chin J Dent Res, 4(4): 7-15.

Du H, Bai YX, Zhu H (2008). An investigation of the knowledge about malocclusions and orthodontic treatment in Beijing area. Beijing $J$ Stomatol, 16(6): 329-331.

Cunningham SJ, Hunt NP (2001). Quality of life and its importance in orthodontics. J Orthod, 28: 152-158.

Hunt O, Hepper P, Johnston C, Stevenson M, Burden D (2001). Professional perceptions of the benefits of orthodontic treatment. Eur J Orthod, 23(3): 315-323.

Linder-Aronson S, Bjerrehorn K, Forsberg CM (2002). Objective and subjective need for orthodontic treatment in Stockholm County. Swed Dent J, 26(1): 31-40.

Lew KK (1993). Attitudes and perceptions of adults towards orthodontic treatment in an Asian community. Community Dent Oral Epidemiol, 21(1): 31-35.

Mandall NA, McCord JF, Blinkhorn AS, Worthington HV, O'Brien KD (2000). Perceived aesthetic impact of malocclusion and oral self-perceptions in 14-15-year-old Asian and Caucasian children in greater Manchester. Eur J Orthod, 22(2): 175-183.

\footnotetext{
*Corresponding author: Yang-xi Chen

Address: Department of Orthodontics, West China College of Stomatology, Sichuan University, 14 Ren Ming South Road, Chengdu, Sichuan, 610041, China

Tel: 862885503081 E-mail: cyxlfx@tom.com
} 